Collins, L. C. \& James, D. (2011) "Exploring transformative learning opportunities as part of the delivery of a video-based intervention." Journal of Applied Linguistics and Professional Practice 8:2 209-229. doi: 10.1558/japl.v8i2.209

\title{
Exploring transformative learning opportunities as part of the delivery of a
}

\section{video-based intervention}

\section{Luke Collins}

NIHR National Biomedical Research Unit in Hearing, University of Nottingham, UK

\section{Deborah James}

Faculty of Health and Life Sciences, Northumbria University, Newcastle upon Tyne, UK and NIHR National Biomedical Research Unit in Hearing, University of Nottingham, UK

\section{Abstract:}

A teacher of the deaf reported a change in perspective following her involvement as a participant in a therapeutic intervention known as video interaction guidance (VIG). We applied a model of transformative learning to validate this report and to explore how this process was initiated. We analysed the transcriptions of two video selections from a 35 minute therapy intervention session with the teacher of the deaf for indicators of stance. The teacher of the deaf's change in stance is mapped in her discourse throughout the session to explore this learning process. The proposition is that particular discourse components can trigger a transformative learning process. Our analysis showed that the participant frequently used binary distinctions to structure their talk subsequent to the guide having introduced a dialectic exploration of a binary proposition. The object of the learning extends beyond the video component as the participant situates this learning in their wider communicative practices. We explore the ways in which the intervention facilitated this learning process and discuss the ways in which the potential for learning can be maximised. 
Keywords: transformative learning, video intervention, conversation analysis, teacher of the deaf, stance, binary. 


\section{Exploring transformative learning opportunities as part of the delivery of a video-based intervention}

\section{Luke Collins}

NIHR National Biomedical Research Unit in Hearing, University of Nottingham, UK

\section{Deborah James}

Faculty of Health and Life Sciences, Northumbria University, Newcastle upon Tyne, UK and NIHR National Biomedical Research Unit in Hearing, University of Nottingham, UK

\section{Introduction}

Video feedback is being effectively used with groups of qualified health professionals to develop clinical reflexivity. This approach provides space for clinicians to analyse and discuss a particular clinical scenario together and has been demonstrated to produce practical outcomes that have significant impacts for patient care and patient safety during complex clinical environments where individuals collectively take responsibility for an outcome (Iedema, 2011). Video footage provides the opportunity for reflection on everyday actions and can also provide an opportunity for reflexivity, where outcomes are expected to extend beyond a specific targeted behaviour into the realm of the social context in which complex tasks are co-constructed. Video Interaction Guidance (VIG) is a method that uses video feedback in one-to-one sessions in the workforce development context (James et al. in press) or as a family intervention (for a meta-analysis, see Fukkink 2008; Häggman-Laitila 2010; Kennedy et al. 2011).

In this paper we seek to demonstrate the process of reflexivity that occurred during a one-toone session of VIG with a teacher who was expressing concerns over her efficacy in her job role. Following the first VIG session the teacher stated in an e-mail to the intervention guide, the second named author of this paper, that the session had had a significantly positive impact on her self-confidence. In further correspondence she has stated that her perception of this 
impact has been maintained over a subsequent period of two years. This paper looks to understand the ways in which the intervention facilitated this increase in self-confidence, considering this change in perspective as the outcome of a transformative learning process (Mezirow 1995). Furthermore, we explore the interactive work of the guide in instigating this change, aspects of stance in the discourse, and the prevalence of binary opposites observed in the discourse of the teacher of the deaf during the learning moment as contributors to the learning process. Understanding such features of the discourse could be important in better administering the intervention as a tool that creates transformative learning opportunities for service providers and families of deaf and hard of hearing children.

\subsection{Video Interaction Guidance}

Video Interaction Guidance (VIG) is an intervention based on the observations of real life communicative events captured on video, selected to demonstrate strengths in the dyad by evidencing successful communication between, in this instance, the teacher of the deaf and their hearing impaired pupil. The social constructivist foundation of VIG (Murray and Trevarthen 1985; Vygotsky 1978) means that it focuses on the relational aspects of communication rather than viewing communication as a competency of the individual. All trainee VIG guiders are assessed in their conversational skills at three assessments before they are accredited as autonomous practitioners of VIG (Kennedy et al. 2011). In VIG the primal basis of communication is seen as social contact, therefore enhancing contact through greater awareness of the principles of contact is considered to be a mechanism by which more successful interpersonal interaction can be gained.

During VIG the focus is on highlighting moments of attuned interaction between participants where initiatives made by the participants are acknowledged and responded to. Attuned 
responses differ from discordant responses where the initiatives are not actually perceived or responded to by the participants. The quality of the initiative and response, i.e., attuned or discordant, is identified through close examination of film footage which is captured in the natural environment. An indicator that an initiative has been received rather than ignored will be visible through verbal and non-verbal behaviour such as in eye-gaze, nodding, speakers moving towards each other, speakers positively affirming by saying 'yes', and speakers repeating what was said in the prior speaker's turn. Attuned interaction between participants is typically preceded by attentiveness and expressions of positive affect. In VIG these aspects of communication are relationally defined in the dyad in a set of contact principles describing multileveled communicative acts, patterns and elements of behaviour (see Appendix A). The guide uses these contact principles to select successful moments of interaction between the participants in the dyad, which are then shown back to the participant in video review sessions.

Participants are informed prior to the intervention that the aim is to raise awareness of the more discrete behaviours that create good communication. The participants are asked to identify a specific context or aspect of their interactions where they would like to look at those behaviours in more detail, though this can also be a more exploratory analysis of their interactions in general. In video review sessions, which follow the recording of the participant in interaction with the child, the guide uses co-inquiry and a coaching style of communication to uncover the participant's response to the events on the video. Their role is to construct new meaning that is created from both the participant's and the guide's contributions in the conversation to create an understanding of the success of the moment and the aspects of the interaction that determined success. The resources for such success are already existent within the family unit; it is primarily perception, not ability that is altered. 


\subsection{Case study}

The participant of the intervention was a teacher of the deaf. The teacher's initial training had been in early years' education and she had moved from a mainstream teaching role to special education in the previous two years. She worked in a school for children with hearing impairment and complex needs. The teacher of the deaf's involvement in the intervention was prompted by her own concerns about her efficacy in her role and recommended by her colleague. An introductory workshop showing the VIG intervention was run by the guide. After attending the workshop the teacher self-selected to undertake VIG, electing to focus on her interactions with an eight-year-old pupil in which she lacked confidence. She was aware that the VIG intervention would focus on moments that showed her to be in positive relationship with the boy. The intervention was discussed with the boy's parents and written consent for the guide to view and edit the films of the teacher working with the boy was gained prior to any work being undertaken. The boy was eight years old. He had profound hearing impairment and a cochlear implant. He was receiving services for children with autism spectrum disorder and was diagnosed with Attention Deficit Hyperactivity Disorder (ADHD). He is one of triplets, having a brother and a sister. Subsequent to her own involvement in VIG, the teacher of the deaf advocated that the family themselves partake in the intervention, which they did. For a report on the experience and outcomes for the family members see the second named author's chapter in Kennedy et al. (2011).

In this case the first film was taken of the teacher and the boy interacting during a trip to a local garden centre. The film was 60 minutes in total. Two short extracts from the film were selected because they showed one piece of attuned interaction between the teacher and the pupil. These two extracts were shown to the teacher during a video review session. By the 
end of the first video feedback session the teacher was able to recognise how the interactions were successful.

\subsection{Transformative learning}

For the teacher of the deaf there was a distinct change in perspective, which we explore as indicative of transformative learning, a theory of learning which posits that 'For learners to change their 'meaning schemes' (specific beliefs, attitudes, and emotional reactions), they must engage in critical reflection on their experiences, which in turn leads to a perspective transformation' (Mezirow 1991: 167). The participants' understanding of how they interact with and influence the behaviour of others is the means by which their perceptions of selfefficacy and overall empowerment can be improved. Based on his work on a national (U.S.) study of women re-entering college education after a long hiatus, Mezirow (1978a, 1978b) established ten phases of perspective transformation as follows:

1. A disorientating dilemma

2. Self-examination with feelings of guilt or shame

3. A critical assessment of assumptions

4. Recognition that one's discontent and process of transformation are shared and that others have negotiated a similar change

5. Exploration of options for new roles, relationships and actions

6. Planning of a course of action

7. Acquisition of knowledge and skills for implementing one's plans

8. Provisionally trying out new roles

9. Building of competence and self-confidence in new roles and relationships

10. A reintegration into one's life on the basis of conditions dictated by one's new perspective. 
He asserts, however, that the ten phases may not present strictly in this order.

The theory posits that the recognition of an inconsistency or contradiction between the knowledge based on our own experiences and a new proposition causes us to critically reflect on the basic assumptions of our meaning schemes. As we work to integrate a new proposition within our meaning perspective there is a process of transformation. This extends beyond reflecting on our own behaviour and calls into question the origin of our perspective and our assumptions. Researchers have been able to identify the ten phases of the model as outcomes of qualitative data (King 2004; Kitchenham 2006; Cheney 2010; Madsen 2010); however, it is argued that 'at this point in the growth and understanding of transformative learning theory researchers should have turned their attention to the process of transformation rather than transformation as an evaluation of success or endpoint' (Snyder 2008: 169), with the suggestion that 'Close analysis of participant conversation will allow for the opportunity to document validity testing, a precursor to changes in meaning perspective' (Snyder 2008: 177). To this end, we examine the conversational data for evidence of each phase of the transformative learning process and elements of the conversation which led up to it.

\subsection{Learning through binary constructions}

We are interested in the ways in which VIG can bring about change for individuals when the focus is on strengths only. We refer to a developmental theory of how children learn using binary oppositions to develop discrimination between concepts (Egan 1993). Egan (1993) states that a principle of binary oppositions facilitates our assimilation of (new) concepts as children. It is a fundamental learning principle through which we engage with and expand our knowledge of core concepts of, for example, good/bad, security/fear, health/sickness, permitted/forbidden, which is followed by a 'mediating principle' as more complex concepts 
are assimilated (hot/warm/mild/cool/cold). As continuing or adult learners, we readily integrate more complex ideas into pre-existing mediated constructs. But this foundation of knowledge is in part what constitutes our 'meaning perspective' and dictates how we assimilate new experiences into our understanding. Transformative learning occurs when this 'meaning perspective' is called into question and we have to critically assess those fundamental constructs that shape our understanding. Do we revert back as far as to restructure our knowledge around those fundamental binary constructs?

An application of Egan's theory to the VIG intervention might help explore the mechanisms of change in the intervention. If learning is underpinned by a bias towards the binary/mediation model then the discussion of the binary opposite of strength (i.e., weakness) should occur as a natural response to the focus on strength/success. Therefore the focus on strength serves to create a disorientating dilemma and perhaps an especially potent one where a binary opposite (failure or need for improvement) is prominent. This idea can be tested in part by analysing the discourse that takes place at and subsequent to a moment of disorientation, which should therefore happen after viewing a moment of strength or success and which is the first step in the sequence of perspective transformation.

Using the conversational data from the session reported to have generated a change in the participant's self-confidence, we explore the following questions:

1. Is the change in perspective indicative of a transformative learning process? Can we find evidence for learning through binary constructions within this process of transformative learning?

2. How was this change in perspective facilitated through conversation? 


\section{Method}

\subsection{Data}

Our data are taken from the preliminary video review session involving the teacher of the deaf, based around video clips of her in interaction with the eight-year-old profoundly deaf student. Given the complex needs of the pupil, there were particular communicative challenges for the teacher of the deaf which she wanted to explore using the video work of the intervention. The film was taken during an educational visit to a garden centre and microanalysed to find moments of particularly successful interaction using the contact principles as a framework for clip selection (Appendix A). The clips were played back to the teacher of the deaf with the guide in the video review session which was video recorded and lasted 35 minutes. From the video review session, two clips were selected: one from within the first 8 minutes of the session (A) lasting 81 seconds and the second (B) from the final 10 minutes, lasting 71 seconds. The first clip was chosen for this case study because it captured what might be described as the 'edge' or the 'threshold' (Berger 2004) to a state of critical reflection that went on to unfold. The second clip was chosen to demonstrate the depth of the perspective transformation and this is especially evident when it is held in comparison to the teacher's stance in the first clip. Each of these clips was transcribed according to a system derived from Jefferson (2004) (see Table 1) and explored for conversational features that would contribute to our understanding of the learning process. This type of transcription indicates prosodic and intonation features as contextual cues (Gumperz 1982), to capture the meaning of what is said in how it is said. In the context of the video review session, where the interlocutors are positioned beside one another and both facing a computer screen displaying the video clips, the level of gestural cues and body language is somewhat limited. [INSERT TABLE1 NEAR HERE] 


\section{Table 1}

\section{Transcription symbols adapted from Jefferson (2004)}

\begin{tabular}{|c|c|}
\hline [ ] & Square brackets mark the start and end of overlapping speech. \\
\hline$\uparrow \downarrow$ & $\begin{array}{l}\text { Vertical arrows mark a gradual change in volume of speech; } \\
\downarrow \text { indicating a decrease, } \uparrow \text { an increase. }\end{array}$ \\
\hline Underlining & Signals a vocal emphasis upon specific words. \\
\hline$(0.2)$ & $\begin{array}{l}\text { Numbers in round brackets measures pauses in seconds, in this } \\
\text { case: } 2 \text { tenths of a second. }\end{array}$ \\
\hline (.) & A micro pause, discernible but too short to measure. \\
\hline Dela::yed & $\begin{array}{l}\text { Colons show degrees of elongation of the prior sound; the more } \\
\text { colons, the more elongation. Measured by one per syllable length. }\end{array}$ \\
\hline »Quick»» & $\begin{array}{l}\text { 'Greater than' signals enclose speeded up talk. Double arrows can be } \\
\text { used to signal rapid increase in speed. }\end{array}$ \\
\hline «Slow» & $\begin{array}{l}\text { 'Lesser than' signals enclose slowed talk. Double arrows can be used } \\
\text { to signal sharp decrease in speed. }\end{array}$ \\
\hline When=although & $\begin{array}{l}\text { Equal signs mark the immediate 'latching' of changed successive talk } \\
\text { with no interval. }\end{array}$ \\
\hline $\begin{array}{l}\text { Having said }- \text { it } \\
\text { is not }\end{array}$ & $\begin{array}{l}\text { Hyphen is used within a sentence marking the connection of successive } \\
\text { talk with an interval (usually used when successive talk changes in } \\
\text { structure and meaning but is also used when meaning stays the same). }\end{array}$ \\
\hline Heh & Voiced laughter. \\
\hline S(h)o F(h)unny & Laughter within speech signalled by 'h's in brackets. \\
\hline
\end{tabular}

\subsection{Analysis}

The aim of the intervention is to raise awareness of the communicative behaviours that lead to successful communication. The expectation is that this will not only provide participants with the knowledge of how to replicate and increase occurrences of successful communication but also that they will feel more confident in doing so. By looking closely at the discourse of the participant throughout the intervention we anticipate a change in this level of confidence and this change in perspective which emerges in the dialogue is explored through the concept of 'stance'. 
'Stance', as Biber and Finnegan (1989: 93) state, is 'the lexical and grammatical expression of attitudes, feelings, judgements, or commitment concerning the propositional content of a message'. It is seen to be intertextual, intersubjective and dialogic (Damari 2009), emphasising the context in which indicators of stance are delivered but also the ways in which stance-taking develops in interaction, as the object of interactional work (Jaffe 2009).

Stance has long been linked to 'modality' (Halliday 1994; Stubbs 1996; Fairclough 2003), as an indicator not only of the commitment to one set of ideas but also of the actor's receptiveness to new ideas (White 2003). Modality is indicated most overtly in the use of modal verbs 'can/could', 'may/might', 'will/would', 'shall/should' (Carter and McCarthy 2006). We are also interested in the way in which core grammar principles of tense and aspect situate the participant's knowledge about previous and current interactions in relation to what they observe in the video as a form of evidentiality. We anticipate that what is observed in the video clips will have an effect on future interactions and that a change in perspective will allow the participants to speculate about the effects of this new level of knowledge.

The dialogic aspect of stance-taking parallels the way in which meaning is co-constructed between the participant and the intervention guide. If we consider Du Bois' (2007) concept of the stance triangle, we find a model for the interactions within the intervention and for our analysis of them. To begin with, the participant and child are recorded in interaction where there is a 'shared stance object' (Du Bois 2007: 159), which can be a material item such as a toy, or an abstract aspect such as a task or manner of play. In the video review session the 'shared stance object' is the video itself as the guide and participant align themselves to its content and to each other. In the conversation that is generated around the video, the 'shared 
stance item' is a new way of thinking, where the participant is confident in her

communicative behaviours. What we aim to explore in the transcript data is the ways in which the participant aligns herself with this concept and the interactional work done by the guide to facilitate this stance-taking.

\section{Findings}

We observe the ten phases of transformative learning within the discourse, which are mapped in Table 2. [INSERT TABLE 2 NEAR HERE]

Table 2 Transcript and transformative learning phases

\begin{tabular}{|c|c|c|c|}
\hline \multicolumn{3}{|c|}{ Transcript A: Video Clip 1 [81s] } & Transformative \\
\hline \multicolumn{3}{|c|}{ G\#: Guide. P\#: Participant. } & Learning Phase \\
\hline $\begin{array}{l}\text { A. } 1 \\
\text { A. } 2 \\
\text { A. } 3 \\
\text { A. } 4 \\
\text { A. } 5 \\
\text { A. } 6\end{array}$ & $\begin{array}{l}\text { P\# } \\
\text { G\# }\end{array}$ & $\begin{array}{l}\text { And just have a look again and see (.) erm } \\
(1.6) y^{\prime} \text { know sort of celebrate really the fact } \\
\text { that given all of that (.) you were still - } \\
\text { this was a successful moment for you both } \\
\text { Mhmn } \\
\text { Yeah? }\end{array}$ & $\begin{array}{l}\text { 1. Disorientating } \\
\text { dilemma }\end{array}$ \\
\hline $\begin{array}{l}\text { A. } 7 \\
\text { A. } 8 \\
\text { A. } 9 \\
\text { A. } 10\end{array}$ & P\# & $\begin{array}{l}\text { I think just for that three second (.) time } \\
\text { I was very (.) stressed at the time so I was } \\
\text { aware - >it was the first time I was videoed< } \\
\text { so I was aware- erm (.) }\end{array}$ & $\begin{array}{l}\text { 2. Self- } \\
\text { examination }\end{array}$ \\
\hline $\begin{array}{l}\text { A. } 10 \\
\text { A. } 11 \\
\text { A. } 12 \\
\text { A. } 13 \\
\text { A. } 14 \\
\text { A. } 15 \\
\text { A. } 16\end{array}$ & $\begin{array}{l}\text { G\# } \\
\text { P\# }\end{array}$ & $\begin{array}{l}\text { in m:y head that he was gonna maybe sign back } \\
\text { [Mhmm } \\
\text { =[because I had too high expectations of him } \\
\text { at that point (.) } \\
\text { Yeah and I didn't really give him ti:me (.) } \\
\text { to explore his environment. }\end{array}$ & $\begin{array}{l}\text { 3. Critical } \\
\text { assessment of } \\
\text { assumptions }\end{array}$ \\
\hline $\begin{array}{l}\text { A. } 16 \\
\text { A. } 17 \\
\text { A. } 18 \\
\text { A. } 19 \\
\text { A. } 20 \\
\text { A. } 21\end{array}$ & $\begin{array}{l}\text { G\# } \\
\text { P\# }\end{array}$ & $\begin{array}{l}\text { let him explore where he was before } \\
\text { then asking him } \\
\text { Okay } \\
\text { Yeah maybes? } \\
\text { I don't [know }\end{array}$ & $\begin{array}{l}\text { 5. Exploration of } \\
\text { options for new } \\
\text { actions }\end{array}$ \\
\hline $\begin{array}{l}\text { A. } 22 \\
\text { A. } 23 \\
\text { A. } 24 \\
\text { A. } 25 \\
\text { A. } 26 \\
\text { A. } 27 \\
\text { A. } 28 \\
\text { A. } 29 \\
\text { A. } 30 \\
\text { A. } 31 \\
\text { A. } 32\end{array}$ & $\begin{array}{l}\mathrm{P} \# \\
\mathrm{G} \# \\
\mathrm{P} \# \\
\mathrm{G} \# \\
\mathrm{P} \# \\
\mathrm{G} \# \\
\mathrm{P} \# \\
\mathrm{G} \# \\
\mathrm{P} \#\end{array}$ & $\begin{array}{l}\text { [You're thinking about what you } \\
\text { should have done } \\
\text { Yeah } \\
\text { Can you- can you - The [point here- } \\
\text { [Where I did do good, right } \\
\text { Ye: : [ah } \\
\quad \text { [Where I did do well, right } \\
\text { Yeah Let's focus on } \\
\text { [Right } \\
\text { =[what you [did do *name* } \\
\text { [Right Right hehheheh }\end{array}$ & Interactional work \\
\hline
\end{tabular}




\begin{tabular}{|c|c|c|c|}
\hline & & & \\
\hline A.33 & G\# & It is str-(uhhuh) & \\
\hline A. 34 & P\# & Right & \\
\hline A. 35 & G\# & It is stressful being vide $(h)$ oe $(h) d$ & \\
\hline A. 36 & P\# & Mm $\quad$ Aahhuh & \\
\hline A. 37 & G\# & And it is ha:rd but & \\
\hline A. 38 & P\# & Right & \\
\hline A. 39 & G\# & Th- the aim here is to focus on [how & \\
\hline A. 40 & P\# & [Right & \\
\hline A. 41 & G\# & =you did it here & \\
\hline A. 42 & P\# & [Right & \\
\hline A. 43 & G\# & [Let's explore & \\
\hline A. 44 & P\# & [Right & \\
\hline A. 45 & G\# & this & \\
\hline A. 46 & P\# & [ Right & \\
\hline A. 47 & G\# & [together & \\
\hline A. 48 & P\# & Just this [bit not & \\
\hline A. 49 & G\# & [Yeah? & \\
\hline A. 50 & P\# & =not what had gone on before & \\
\hline A. 51 & G\# & Yep & \\
\hline A. 52 & P\# & Just [ that clip & \\
\hline A. 53 & G\# & [Is that okay? & \\
\hline A. 54 & P\# & [Right $\uparrow g \circ$ on then & \\
\hline A. 55 & G\# & [Yep just this tiny bit we'll watch it again. & \\
\hline Trans & crip & : Video Clip 2 [71s] & \\
\hline B.1 & P\# & even I have sessions like this videoing Mum (.) & 4. Recognition that \\
\hline B. 2 & G\# & Yeah (.) yeah & discontent is \\
\hline B. 3 & P\# & And Mum's & shared and athers \\
\hline B. 4 & G\# & $=$ Yeah & snared and others \\
\hline B. 5 & P\# & seeing the positives (.) & negotiated change \\
\hline B. 6 & G\# & Yeah & \\
\hline B. 7 & P\# & I think that would & \\
\hline B. 8 & G\# & yeah & \\
\hline B. 9 & P\# & $=r e a l l y$ & \\
\hline B. 10 & G\# & yeah & 6. Planning a \\
\hline B. 11 & P\# & $=$ really really help & course of action \\
\hline B. 12 & G\# & okay & \\
\hline B. 13 & P\# & $=\operatorname{Mum}()$. & \\
\hline B. 14 & G\# & So we could work towards that then (.) & \\
\hline B. 15 & P\# & Yea:h & \\
\hline B.16 & G\# & Maybe $\left[{ }^{\star}\right.$ name* $]$ & \\
\hline B. 17 & P\# & [But I don't & \\
\hline B. 18 & G\# & =Yeah & \\
\hline B. 19 & P\# & =know how Mum would fe: :el (.) & knowledge and \\
\hline B. 20 & G\# & Yeah (.) No [it's okay (.) & skills for \\
\hline B. 21 & P\# & {$[$ at the mo:ment (.) } & implementing \\
\hline B. 22 & G\# & $=I t^{\prime} s$ a (.) it's (.) it's (.) it's a [yeah] & one's plan \\
\hline B. 23 & P\# & [I think she & one s plan \\
\hline B. 24 & & would have to see me first & \\
\hline B.25 & G\# & Yeah (.) Sure (.) [Yeah & \\
\hline B. 26 & P\# & [And then $\mathrm{y}^{\prime}$ know (.) & 8. Provision of \\
\hline B. 27 & G\# & Yeah & trying new roles \\
\hline B. 28 & P\# & Maybe s (.) She might even suggest it [herself & \\
\hline B. 29 & G\# & [Ye::ah Yeah (.) & \\
\hline B. 30 & & No [it really is up to you & \\
\hline B. 31 & P\# & {$[$ So } & \\
\hline B. 32 & G\# & it's really your y'know it's for & \\
\hline B. 33 & & you to think about how you want to use it & \\
\hline B. 34 & P\# & Yeah & \\
\hline B. 35 & G\# & Totally & \\
\hline B. 36 & P\# & =Yeah (.) yeah & 9. Duiluing or \\
\hline B. 37 & G\# & Yea:h & competence and \\
\hline
\end{tabular}




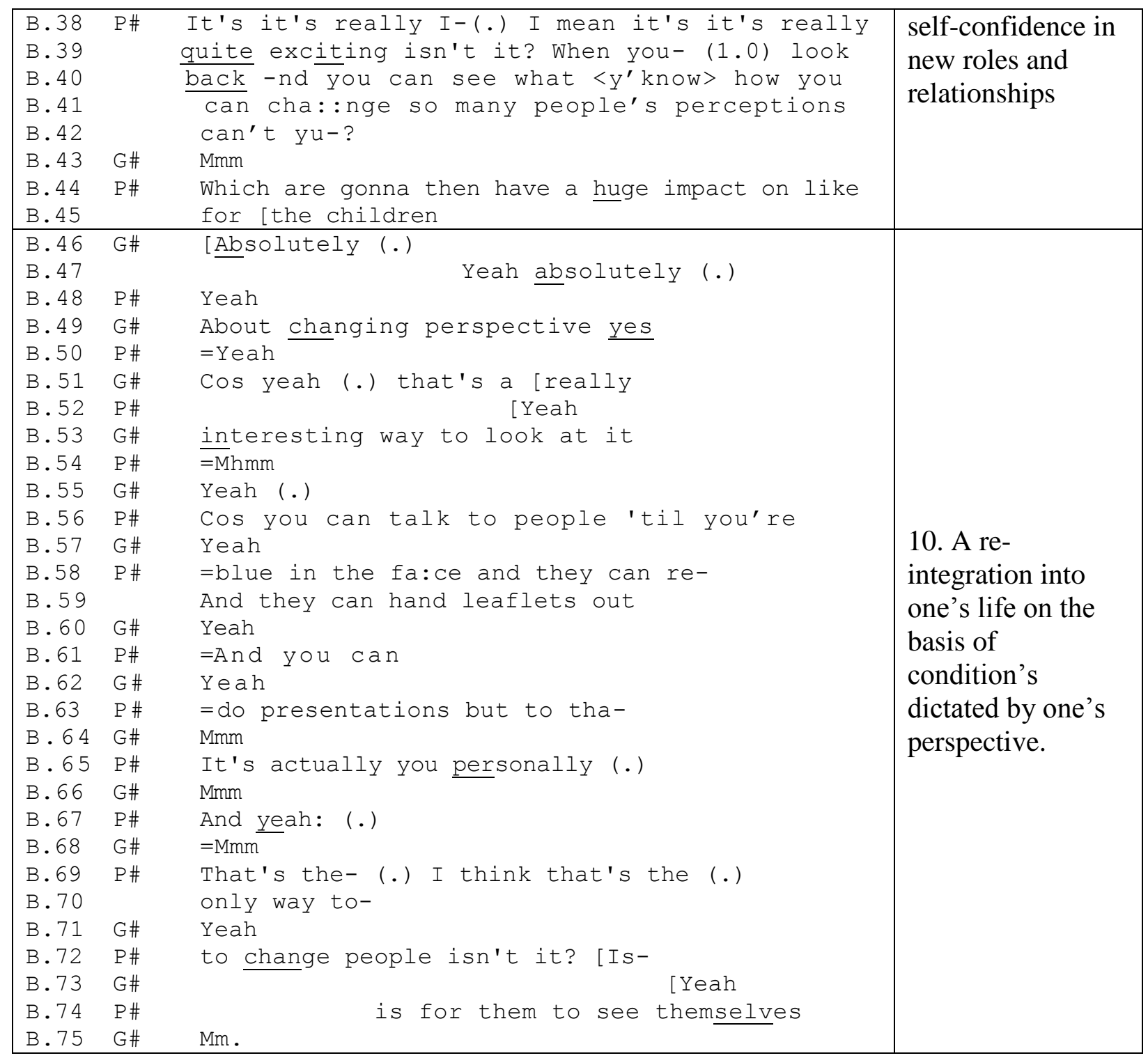

If we consider each of the phases and the associated extracts we can look more closely at the components of the discourse and aspects of stance-taking:

\section{Disorientating dilemma}

The moment of disorientation is conveyed in the participant's 'Mhmn', which constitutes a conversational turn and the reception of the proposition but does not align her with what has been said. The guide provides another opportunity for the participant to align herself with this idea by asking 'Yeah?' but the participant verifies their dis-alignment with the proposition in the subsequent vindication of her behaviour. 


\section{Self-examination}

The participant's circumstantial explanation is contextualised through the adverbial clauses 'just for that three second time' [A.7] and '[It was] the first time I was videoed' [A.9]. The repeated use of 'so' as a causal conjunction is an attempt to link the identified problem state, 'I was very stressed' [A.8], 'It was the first time I was videoed', with the effect of making the participant very 'aware'[A.9]. The affective stance, 'I was very stressed' is maximised by the use of 'very' and emphasised through intonation markers. The disorientating unfamiliarity, 'the first time' generates a heightened 'aware[ness]', which in this context is seen to be negative.

The episode is reported in the past tense ('I was very stressed', 'I was aware', 'I was videoed') and with a passive construction. However, the participant's understanding of it is being worked out in the moment, the present tense 'I think'[A.7], which would explain the interrupted grammatical construction, change in tempo and sporadic pauses. There is a contrast developing between the 'then' with its associated affective stance, and 'now', which is evaluated in terms of epistemic stance.

\section{Critical assessment of assumptions}

As the participant becomes critical of her assumptions we observe a continuation of time signifiers, locating the episode 'at that point' [A.14]. This is contrasted with the conceptual freedom of one's own time, 'giving him time' [A.15], which is made to seem even more liberating by the word 'explore' [A.16]. We also observe a semantic polarisation between 'expectations': what is presumed to be known; and 'explore' which ventures into the unknown. The critical assessment of those original assumptions is that they were 'too high' 
[A.13], that the participant 'didn't really give him time'[A.15] where maximal items 'very' and 'really' emphasise the extent of this error. The participant now expresses uncertainty of those expectations 'he was gonna' with a post-corrective 'maybe' [A.11].

If we consider the grammatical structures of the participant's discourse in this passage, they gradually align more closely with the child. In the first clause structures the subject is ' $\mathrm{I}$ ', the object 'targets'[A.10], the dative 'my head' and the child ('he') is relegated to a subordinate clause. In the following clause construct the subject 'I' holds another cognitive element as the object: 'expectations' [A.13]. The child is included in this clause as the indirect object, 'of him'. Finally, the subject 'I' has a direct relationship with the object 'him' (not giving him time) [A.15], and the child as subject dominates the subordinate clause, 'to explore his environment'. Semantically, this also posits the speaker and the listener in the surroundings of the child, in 'his environment'.

\section{Exploration of options for new actions}

Though the 'I' is once again the subject, the child 'he/him' becomes the focus in this sentence as the direct object, 'let him', 'asking him', and then also becomes the subject, 'where he was'[A.17-18]. Again, the child has the possibility to 'explore', he is permitted ('let him'); 'he' is the subject and has the privilege of communicating back when the speaker 'ask[s] him'. The participant conveys doubt when they ask for confirmation, 'Yeah maybes?' but takes the turn before the guide to declare uncertainty 'I don't know'. By framing this exploration with the modal verb 'should' the participant aligns themselves to an expectation of what she 'should' have done. Here, the participant has introduced an alternative founded on some external agency, relating it to the present through the temporal progression from 
'should' in the past tense, to imagining the outcome in a hypothetical progressive tense, 'asking him', with the conjunction 'before' marking this progression.

\section{Interactional work}

It is at this point that the guide is prompted into redirecting the participant's focus, to realign her stance. The participant has introduced an external agency, dictating what she 'should' have done and ultimately descended into an exclamation of uncertainty 'I don't know'. The guide had already begun to respond, drawing attention to the fact that the participant is 'thinking about what [she] should have done' [A.22-23] before setting up an alternative. The participant is of course already familiar with the premise that the intervention focuses on strengths. The guide's self-correction from a request 'Can you' to an explanation of the process, 'The point here' [A.25], perhaps to avoid putting any unnecessary demands on the participant, is interrupted by the participant who assumes the conversational turn to acknowledge the idea of focusing on 'Where I did do good, right' [A.26]. Over the subsequent thirty lines of the transcript the participant repeats and reiterates this concept to herself, as an exploration of that disorientating dilemma, 'where I did do well'.

The guide aligns both him/herself and the participant with the premise through collective pronouns 'Let's focus on' [A.29], 'Let's explore this together' [A.43-47], an empathetic stance, 'it is stressful being videoed'[A.35], 'it is hard' [A.37] and by reciprocating her laughter [A.32-33]. The guide acknowledges the affective stance of the participant but then pre-empts an alternative stance with a stress on the preposition 'but'[A.37]. The participant's repetitive use of 'Right' demonstrates her willingness to now engage with the concept and to help her own assimilation makes a subsidiary binary comparison, 'Just this bit', 'not what had gone on before' [A.48-50], and again 'Just that clip' [A.52]. The degree of overlapping in this 
short passage shows that the guide and participant are co-constructing at the level of conversational turn. The participant is then able to proceed, giving the literal 'go ahead' to the guide ('Right, go on then') [A.54], now seemingly aligned with the aims of the intervention and the stance of the guide.

\section{Recognition that one's discontent and the process of transformation are shared and that others have negotiated a similar change}

In the second clip, which comes from the final 10 minutes of the session we resume the transformative learning process with phase 4 , where the participant likens her experience to that of others. This follows a more in-depth discussion of the specific events of the video as the guide and the participant explore the strengths within the interaction. Having assumed the role of 'learner' during this period, the participant makes the comparison with the mother, who is 'seeing the positives' [B.5]. Mezirow (1991: 11) states that in transformative learning, individuals 'reinterpret an old experience (or a new one) from a new set of expectations, thus giving a new meaning and perspective to an old experience'. The events of those sessions have not changed but the participant's perspective of them has. In the role of participant, the teacher of the deaf is able to reassess her role as guide when working with the mother and her overall outlook is improved. The comparison is made, 'like this' [B.1], between the sessions that she participates in and those she guides with the mother as participant. The outcome is that 'Mum's seeing the positives', from which we can infer that the speaker herself is able to 'see the positives'. This all occurs in the present progressive tense, 'I have', 'videoing Mum'[B.1], 'Mum's seeing', indicating that this is not only a current assessment but one which is ongoing.

\section{Planning a course of action}


The participant here considers involving the mother in the video review sessions, using the modal verb 'would' to convey likelihood [B.7]. The hyperbolic use of maximizers 'really really really' and the idea of 'help' [B.11] emphasise the speaker's enthusiastic stance. This assessment is posited in the present tense as well as the participant's subjective viewpoint, 'I think' [B.7]. The participant's positive reaction to the session is manifest in their confidence that the tool would be of use to the family that she is working with. This suggests that her own confidence is founded in fulfilling her role as a teacher of the deaf. She is not assessing the quality of her own interactions, as demonstrated in the video, but rather her guidance role with the family. It is perhaps in this capacity where the teacher of the deaf had concerns about her efficacy and the subsequent dialogue would suggest that it is in this domain, as a guide being able to use the video intervention, that the teacher of the deaf finds self-confidence.

\section{Acquisition of knowledge and skills for implementing one's plan}

The participant's confidence in her teaching role is manifest not only in the assertion that the mother 'would have to see me first' [B.24] but also in the informed stance-taking, suggesting that the teacher of the deaf knows the mother well enough to anticipate her stance. We know that this is an informed viewpoint through the use of the modal verb 'would', which expresses a hypothetical likelihood. This minimizes the sense of unknowing expressed in 'I don't know' [B.17-19], which based on the intonation we can also assert that this is not an expression of ignorance. On the contrary, it is her surmise of the mother's own affective stance, of how she would 'feel', which is emphasised through elongation.

To substantiate this informed viewpoint the participant expresses likelihood ('would') with the certainty of the mother's compulsions 'would have to'[B.24]. Her privileged viewpoint is expressed in a grammatical relationship as she is the direct object of that very compulsion, 
'she would have to see me', expressed as the speaker's own (informed) opinion, 'I think' [B.23]. Furthermore, this is seen to be a temporary state, located in a 'beginning' stage through the use of the temporal signifiers 'at the moment' [B.21] and 'first' [B.24]. The participant is expressing confidence not only in her level of knowledge of the family but also in what she can provide 'first' before the plan of action can continue. The teacher of the deaf's concerns are in relation to the mother's feelings about being involved in the intervention, which reminds us that the use of video can often be confronting, particularly where there are feelings of doubt about one's own communicative competence. In suggesting that the mother see her first, the teacher of the deaf is already providing an opportunity for the mother to experience Phase 4 of the transformative learning process as someone who had shared the mother's concerns but has 'negotiated change', again re-establishing this role as a guide for the mother and her family.

\section{Provision trying of new roles}

Continuing to assess her role as guide for the family the teacher of the deaf considers the effect of her suggested action and is quite optimistic about being able to convey the advantages, to the point where 'She might even suggest it herself' [B.28] using the adverb 'Maybe' and the modal 'might' to express possibility. The mother carries the agency in the subject position 'She' but also as the speaker reflexively empathises with the mother's stance: 'herself' [B.28]. The teacher of the deaf feels well acquainted enough with the mother to imagine what her course of action might be.

\section{Building of competence and self-confidence in new roles and relationships}

The participant expresses capability in this passage, with the modal verb 'can', which progresses from an intransitive observation 'see', to a transitive action 'change' [B.40-41]. 
The speaker's affective stance is expressed as 'excitement' [B.39], which transpires in her maximizing items 'really', 'really quite', 'so many', 'huge', continuing this maximization of the beneficial effects of this action for 'so many people' [B.41]. The participant's confidence in the intervention is conveyed through speculating about the 'huge impact' [B.44] of changing 'so many people's perceptions' [B.41], the modal item 'can' and the tag questions to the guide, 'isn't it?' [B.39], 'can't yu-?' [B.42]. The participant is also confident of the causal relationship between the conditional clause 'When you look back', that is an enabling action, 'you can see..' [B.39-40]. Furthermore, this has additional implications, which are expressed with certainty 'are gonna then'[B.44].

In comparison to the opening lines of extract A, the participant is feeling 'excitement' [B.39] as opposed to 'stress' [A.8]; they refer to a non-specific, recurring timeframe 'when you look back' [B.39] as opposed to a specific circumstance 'just for that three second time' [A.7]; whereas before the participant used maximizers to express a criticism of her 'expectations'[A.13], here she uses 'really', 'so many', 'huge' to describe the beneficial impact of her actions [B.44]. The way in which the participant perceives the 'looking back' here, relating the outcomes to present and future 'success' is in contrast to her previous onaction reflection of looking back at the video which generated doubt, negativity and ultimately failure.

\section{A reintegration into one's life on the basis of conditions dictated by one's perspective}

The participant engages in the reflective practice of 'seeing themselves' and compares its effect to three alternative actions. The first of these, simply 'talk[ing] to people' [B.56] is given an exhaustive quality, 'til you're blue in the face' [B.58], the enduring quality of which is emphasised through the use of the conjunction 'until'. The accumulative listing of 
these possibilities in a paratactic style, 'And..and...and', adds to this exhaustive effect and is expressive of the futility ('failure') the speaker associates with these actions. The participant contrasts these three alternative actions (talking, handing out leaflets, doing presentations) first with the conjunction 'but', then describing an action which exists in actuality ('actually' [B.65]) and with the individual ("personally' [B.65]), then projecting the applicability of the intervention to the mass noun 'them' [B.74], the 'people' [B.72], where the effect is 'change' [B.72]. Furthermore, this is cited as being the 'only way' [B.70] to bring about change, suggesting a firm stance and thus indicating a full integration of the view that the intervention brings about positive change.

\section{Discussion}

The participant reported that the video review session has had a significant impact on her self-confidence and our analysis of the conversational data shows that this confidence is founded in her role as a service provider for the family: as a teacher of the deaf for the child, but perhaps more pertinently as a guide for the mother. In experiencing the intervention for herself the teacher of the deaf develops confidence in the positive effect of the video intervention; she can report moments where the mother is able to acknowledge positives in their communicative dynamic and perhaps it is knowing that she can utilise such a tool that forms the basis of this confidence. The change in perspective is seen to exhibit the ten phases of transformative learning. However, the object of learning is not specifically the communicative behaviours demonstrated in the video clip but as an extension of this, the potential of the video intervention in bringing about change in people's perspectives. This reiterates that the intervention is not designed to drastically alter behaviours and that good communication practices are already existent within the dyad. Rather the intervention raises awareness of the instances of attuned interaction and allows the participant to find their own 
meaning beyond that. For this participant, an effective demonstration of that process generated confidence that she could bring about a similar change for the family. It is the nature of the intervention and the co-construction process of the video review session that meaning for the participant is negotiated through the evidence provided by the guide's selection of the clips and the way in which the participant relates the content of the video to her role in the communicative dynamic. The guide even refers to this in the second transcript when she says 'it's for you to think about how you want to use it' [B.32-33].

The guide facilitated this process by redirecting the participant's focus early on in the video review session. The approach the participant initially took in reflecting on the video was indicative of their negative stance on their relationship with the student and the discord between the guide's and the participant's approaches to the video conveys this binary construct of success/failure. Between the initial 'negative' approach and the transformed perspective of the intervention we also observed binary constructs of then/now, doubt/certainty, the specification of time in context/the concept of non-specific time and 'time to explore', stress/excitement, and the external agency of what one 'should' do/individual agency 'can' which draws in possibility and capability. Furthermore, the participant uses maximizers ('really', 'too') and degree indicators ('so many', 'quite', 'only', 'til you're blue in the face') to amplify and further polarise those binaries. The initial binary construct of success/failure represented the disorienting dilemma and prompted the participant to realign their stance in relation to the focus on strengths. The subsequent use of binary constructs may have facilitated the progression through the transformative learning process but in the very least created distance between the initial negative approach and the eventual perspective that strongly advocates the use of the video intervention. 
Once the guide had redirected the participant towards a stance that focuses on success, they can then allow the conversational space for the participant to find their own meaning from the intervention. In this way, the guide almost appears passive in the transcript, allowing the participant to think out loud and simply acknowledging their contributions with minimal speech tokens such as 'Yeah', 'okay', 'right' as the participant works towards her own outcome. It is the interactional work the guide is involved in just prior to this that facilitates the transformative learning process. What is shown is that even though the video clip was selected for its level of success, the participant was still inclined to identify her own shortcomings. The guide has an evidence base for why the clip is 'successful' and this must be accessible to the participant if she is to realign their stance and change their perspective. Having done this, the guide must be accommodating of the ways in which the participant relates this new perspective to find meaning in her communicative practices outside of the intervention. Our understanding of this level of guidance is a way in which tools that use video reflexivity can create more frequent and better learning opportunities. 


\section{Appendix A}

The Contact Principles of Video Interaction Guidance

Clusters

1. Initiative and reception

2. Interaction

3. Giving guidance:

Discussion
Patterns

being attentive

attuning oneself

making turns

co-operation

forming opinions

giving content

decision making

developing effective

learners

\section{Elements}

turning towards someone looking at someone friendly intonations friendly facial expressions friendly postures participation nodding naming saying "yes"

involvement in group looking round acknowledging reception giving and taking turns evenly sharing turns joint transaction helping one another

giving/accepting/ exchanging /investigating opinions mentioning/developing in-depth discussion of subjects proposing/accepting /amending agreements inviting \& supporting prediction/task description/judgement of time needed/approach/ difficulties/result inviting \& supporting review: progress description/ evaluation of predictions/ attribution of achievements/ accessing 
prior knowledge/ goal

setting

4. Giving guidance:

Conflict management naming contradiction

restoring contact

making transactions investigating intentions

return to $1-2-3$

establishing viewpoints

complying with rules

\section{References}

Berger, J. G. (2004) Dancing on the threshold of meaning: Recognizing and understanding the growing edge. Journal of Transformative Education 2: 336-351.

Biber, D. \& Finegan, E. (1989) Styles of stance in English: Lexical and grammatical marking of evidentiality and affect. Text 9 (1): 93-124.

Carter, R. \& McCarthy, M. (2006) Cambridge Grammar of English. Cambridge: Cambridge University Press.

Cheney, R. (2010) Empirical measurement of perspective transformation, 199-2009. Paper presented at the Midwest Research-to-Practice Conference in Adult, Continuing, and Community Education, Michigan State University, September 26-28, 2010. Retrieved from https://www.msu.edu/ mwr2p/Cheney-MR2P-2010.pdf.

Damari, R. R. (2009) Stancetaking as identity work: Attributed, accreted, and adjusted stances taken by an intercultural couple. In eVox: Georgetown Working Papers in Language, Discourse and Society 3: 18-37.

Du Bois, J. W. (2007) The stance triangle. In R. Englebretson (ed.), Stancetaking in discourse: Subjectivity, evaluation, interaction 137-182 . Amsterdam: Benjamins.

Egan, K. (1993) The Educated Mind. Chicago: The University of Chicago Press.

Fairclough, N. (2003) Analysing Discourse: Textual analysis for social research. London: Routledge.

Fukkink, R. (2008) Video feedback in widescreen: A meta-analysis of family programs. Clinical Psychology Review 28 (6): 904-916. doi: 10.1016/j.cpr.2008.01.003.

Gumperz, John J. (1982). Discourse Strategies. Studies in Interactional Sociolinguistics 1. Cambridge: Cambridge University Press

Häggman-Laitila, A., Seppänen, R., Vehviläinen-Julkunen, K. \& Pietilä, A-M. (2010) Benefits of video home training on families' health and interaction: evaluation based on follow-up visits. Journal of Clinical Nursing 19: 3504-3515. doi: 10.1111/j.13652702.2010.03241.x

Halliday, M. A. K. (1994) An introduction to functional grammar. London: Edward Arnold. Iedema, R. (2011) Creating safety by strengthening clinicians' capacity for reflexivity. $B M J$ Quality \& Safety 20(S1): i83-i86.

Jaffe, A. (ed.) (2009) Stance: Sociolinguistic Perspectives. Oxford University Press. 
James, D. M., Falck, C., Hall, A., Phillipson, J. \& McCrossan, G. (in press) Creating a person-centred culture within the North East Autism Society: preliminary findings. British Journal of Learning Disabilities. doi:10.1111/j.1468-3156.2012.00757.x

Jefferson, G. (2004) Glossary of transcript symbols with an introduction. In G.H. Lerner, (ed.) Conversation analysis: studies from the first generation. Santa Barbara: John Benjamins Publishing Company.

Kennedy, H., Landor, M. \& Todd, L. (2011) Video Interaction Guidance: A relationshipbased intervention to promote attunement, empathy and wellbeing. London: Jessica Kingsley Publishers.

King, K. P. (2004) Both sides now: Examining transformative learning and professional development of educators. Innovative Higher Education 29: 155-174.

Kitchenham, A. (2006) Teachers and technology: A transformative journey. Journal of Transformative Education 4: 202-205.

Madsen, S. R. (2010) Leadership Development in the United Arab Emirates: The transformative learning experiences of women. Journal of Leadership \& Organizational Studies 17: 100-110. doi: 10.1177/1548051809345254.

Mezirow, J. (1978a) Education for perspective transformation: Women's re-entry programs in community colleges. New York: Teachers' College, Columbia University.

Mezirow, J. (1978b) Perspective Transformation. Adult Education 28: 100-110.

Mezirow, J. (1991) Transformative dimensions of adult learning. New York: John Wiley.

Mezirow, J. (1995) Transformation theory of adult learning. In Welton, M. R. (ed.) In defense of the Lifeworld. New York: SUNY Press.

Murray, L., and Trevarthen, C. (1985) Emotional regulations of interactions between twomonth-olds and their mothers. In T. M. Field \& N. A. Fox (Eds.), Social perception in infants, 177-197. Norwood, NJ: Ablex.

Snyder, C. (2008) Grabbing hold of a moving target: Identifying and measuring the transformative learning process. Journal of Transformative Education 6: 159-181. doi: $10.1177 / 1541344608327813$

Stubbs, M. (1996) Towards a modal grammar of English: A matter of prolonged fieldwork. In Text and Corpus Analysis 196-228. Oxford: Blackwell.

Vygotsky, L. (1978) Mind and Society. Cambridge: MA: Harvard University Press.

White, P. R. R. (2003) Beyond modality and hedging: a dialogic view of the language of intersubjective stance. Text 23 (2): 259-284. 